\title{
De Stirner a Nicómaco. Pensamiento sobre el poder desde Max Stirner ${ }^{l}$
}

\section{From Stirner to Nicomacus. Meditation on the power according to Max Stirner}

\author{
RICARDO GUTIÉRREZ AGUILAR \\ CSIC-Universidad de Murcia
}

Recibido: 12-04-2007 Aprobado definitivamente: 18-04-2007

RESUMEN

El presente artículo trata de mostrar la evolución de una concepción del poder concreta que lleva de Hegel a Stirner a través del papel desempeñado por el individuo. De esta forma, el individualismo aparece entre dos líneas enfrentadas de la metafísica y la teoría de la acción.

PALABRAS CLAVE

HEGEL, STIRNER, ACCIÓN, POLÍTICA

\begin{abstract}
This article tries to show the evolution of one specific conception of power that leads from Hegel to Stirner through the role played by the individual. Thus, individualism appears between two conflicting lines of metaphysics and action theory.
\end{abstract}

KEYWORDS

HEGEL, STIRNER, ACTION, POLITICS

1 Para las ediciones críticas de Hegel y Marx empleo las siguientes abreviaturas: Hegel, G. W. F. Werke in zwanzig Bänden. Theorie Werkausgabe. Suhrkampf Verlag. Frankfurt am Main, 1970. (HW seguida del volumen de la edición y la página); Marx, K., Engels, F. Werke. Institut für Marxismus-Leninismus beim ZK der Sed. Dietz Verlag Berlin, 1974 (MW seguido del volumen y la página). Con Stirner emplearé la abreviatura $U P$, seguida de la página, para la edición en Stirner, M. El Único y su propiedad. Prólogo, traducción y notas de José Rafael Hernández Arias. Ediciones Valdemar. Letras clásicas. Madrid, 2004.

(C) Contrastes. Revista Internacional de Filosofía, vol. XIII (2008), pp. 139-155. ISSN: 1136-4076 Licenciatura de Filosofía, Universidad de Málaga, Facultad de Filosofía y Letras Campus de Teatinos, E-29071 Málaga (España) 
CALÍGULA.-Y ¿qué me importa una mano firme, de qué me sirve este asombroso poder si no puedo cambiar el orden de las cosas, si no puedo hacer que el sol se ponga por el Este, que el sufrimiento decrezca y que los que nacen no mueran? No, Cesonia; me es indiferente dormir o permanecer despierto si no puedo actuar sobre el orden de este mundo.

(Camus, A. Calígula. Acto I. Escena XI)

\section{PRecedente: una gigantomaquia estatal}

Allá POR EL AÑo 1822, en Prusia, se tenían claras dos cosas en el terreno de la Filosofía: que Hegel debía ser considerado el pensador oficial del Estado, y que esta hegemonía incontestable no había de durar mucho más.

Hegel acaba de publicar por esos años la última de sus obras capitales, los Fundamentos de filosofía del Derecho (1821) en la cual profundiza en la etapa previa pero vital del proyecto mayor de «desarrollo» que es el del Espíritu absoluto -auténtica razón de ser de toda su filosofía. ${ }^{2}$ En la obra, la segunda desenvoltura del Espíritu, la del espíritu práctico, traza su necesidad como parte en el sistema por medio de la creación de relaciones entre los términos primitivos del mismo, términos ya presentados en la Lógica y, principalmente, en los capítulos V y VI de la Fenomenología. En el orden práctico el Espíritu se concreta bajo el signo de la voluntad ${ }^{3}$ y sólo puede ser entendido dentro del panorama de realización de una libertad a través de la acción, que es su medio. Esto, en términos categóricos, no reporta sino su enclasamiento dentro de la esfera ética-social-política y, el añadido de un presupuesto básico: se trata de una esfera en el Derecho.

2 vid.HW. 3, 22-29 (utilizo su traducción en Hegel, G. W. F. Fenomenología del espíritu. Prólogo. Traducción de Wenceslao Roces y Ricardo Guerra. FCE. Madrid, 2000, pp.15-19; en adelante como $F$ seguido de la página).

3 El espíritu «como voluntad se sabe como aquel que se decide en sí mismo y se completa desde sí, [...] como voluntad, el espíritu ingresa en la realidad efectiva» $(H W .10,288$. Uso su traducción en Hegel, G. W. F. Enciclopedia de las ciencias filosóficas. §469. Alianza Editorial. Madrid, 2005, pp. 511-512; en adelante $E F$ seguido de la página). Lo que se viene a querer decir aquí es que la voluntad toma cuerpo, que «tiende a...»-ad petere, appetitus-, que tiene contenido, con la conciencia del objeto del pensamiento. Esta es su sustancia, término estrechamente relacionado con la Wirklichkeit de la que se habla en la Fenomenología. Sustancia es lo que tiene poder de obrar -wirken- (vid. Díaz, C. «Una realidad a la que Hegel llama Wirklichkeit» en Hegel, filósofo romántico. Prólogo de J. M. Navarro Cordón. Ediciones Pedagógicas. Madrid, 1994, pp.50-51). Es claro, por tanto, que no se podría 'querer' llevar a cabo nada sin idea de qué hacer... 
Política y Ontología son mediada la práxis.

Para Hegel todo lo que el derecho recoge en su constitución como ciencia no es sino la línea del dominio de la libertad, de la «voluntad qua libre», lo que es de por sí un dominio sumamente amplio a la par que complexificado. Así, deberes, derechos, costumbres, anudamientos de lo moral y lo jurídico, son determinaciones llevadas a realización en el inevitable paso dialéctico de la voluntad finita del individuo a la voluntad infinita y universal que sólo puede «querer» su misma libre voluntad. El clásico volo me velle. Esta voluntad sería la causa sui cuya esencia es actividad. Su justa medida y su reencuentro es la ilimitación. De ahí que en ese ejercicio dialógico entre lo que tiene ansias de acabamiento y, el esperado lugar donde se cruzan las paralelas del querer y el poder se deba transitar desde lo particular a lo universal, que es lo mismo que decir del Derecho -en terminología hegeliana- que debe capturar desde el momento del derecho individual que rige el caso al momento de máxima generalidad, que es la ley presente en la eticidad [Sittlichkeit], aquello que no puede lograr ninguna casuística jurídica.

El primer paso en el mundo del Derecho es el de despojarse de la creencia de que lo particular es lo real y asumir que «lo verdadero es el todo. Pero el todo es solamente la esencia que se completa mediante su desarrollo. De lo absoluto hay que decir que es esencialmente resultado, que sólo al final es lo que es en verdad y en ello estriba precisamente su naturaleza [...]». ${ }^{4}$ Esto es lo que explica que durante la compleción del concepto de Estado - una compleción que no es sino ganancia de sentido- que acaba siendo unidad interpretativa mayor o ideal de la acción, el ciudadano se comprenda sólo en relación al margen superior que es este concepto. El derecho realizado es aquel que encardina «la identidad del bien y de la voluntad subjetiva»: ${ }^{5}$ los ciudadanos en la unidad de querer justo que es el Estado; el mismo momento en que las personas encuentran su realidad en el espíritu de su pueblo como deber ser y objetividad.

La sustantividad en Hegel, al igual que la subjetividad personal, se resuelve en la confrontación y el movimiento de acción-reacción o de negación y negación de la negación. Es un movimiento tendente a restablecer el equilibrio sin dejar de permitir que lo concreto de la actividad llegue a ser incesantemente. El espíritu, debe salir de su ipsismo o ensimismamiento individual y hallarse a sí mismo en el mundo concreto de las manifestaciones objetivas, de las actividades de una voluntad convertida en acción racional libre ${ }^{6}$ La acción es «racional» por ser determinada, por tener límites que permiten conocer la pertenencia de todos, alguno o ninguno de los deseos subjetivos a su rango, y, «libre», por no verse

$4 \quad H W .3,24 ; F, 16$.

$5 \quad H W .10,303-304 ; E F, 523$.

6 Vid. HW. 10, 297; EF, 517. 
decidida por instancia alguna exterior y poseer su justificación y legitimidad en el sujeto que la elige.

Se entiende perfectamente según lo visto que la acción de más largo recorrido, la más significativa para nosotros por ello, es aquella que reverbera en las estructuras objetivas más amplias. La ampliación consiste en un saber qué desear de línea amplia. ¿Qué más amplio que el terreno de la universalidad? Aquí es donde la voluntad libre «sabe» que puede querer algo grande e infinito... más importancia aún tiene esto si se cae en la cuenta de que en ese momento, como individuo, «la persona tiene por fin sustancial el derecho de poner su voluntad en toda cosa, la cual, por ello» es suya «de ahí el absoluto derecho del hombre de apropiación sobre todas las cosas» ${ }^{7}$ ya sea por convertirlas en su propiedad, ya sea en su elaboración o mediante simple designación.

¿Su primera posesión? Su derecho a sí mismo, derecho inalienable, su propiedad; ¿reconocer otros propietarios? La entrada en el mundo de lo social, lugar en el que surge el contrato en la voluntad común y el consenso voluntario y, en que la 'vuelta' a la particularidad limitadora, hace surgir también la violación del mismo. La injusticia, la lesión del derecho que ahora comenzaba su tránsito a la inmensidad, es confusión categorial que pretende hacer representar a la norma común la norma de uno solo. Es la propiedad de la misma norma. No hay derecho particular, no tiene sentido a este punto sino como caso e instancia de lo general. Hegel seguramente respondería que, en $s u$ Estado, el acompasamiento entre ley y justicia está tan templado que por definición, en tanto absoluto el Derecho, cualquier desviación del mismo no puede ser sino vulneración de lo que -parafraseando a Kant en su segunda Crítica- 'la Idea se ha dado como norma a través del político'.

En la sociedad civil creada a partir de la puesta en común sobre lo que la circunda -que es en sí el contrato-, yo me reconozco también en los otros. A saber, yo amplío el sentido de lo que entiendo por mi concepto de particularidad a través de lo que los demás han compartido conmigo como propiedad. De ahí que, el anterior pretendido derecho personal, se desdibuje en uno abstracto, cuando lo que tengo ya es una realidad que pone mi «ordo» en lo universal, paradójicamente ahora como concreto: el yo «hace» sólo desde los otros y con los otros. El movimiento dialéctico orienta hacia la esfera superior del Estado por medio de la guía de una conciencia del «Bien» creciente, orientación que depende de que salgamos del nosotros, los particulares, para llegar a lo sumamente externo: lo general. La acción es moral en tanto acción tendente al bien y, ciertamente, se ha convertido en axioma de la conciencia práctica que lo bueno es el objeto de toda intención. Se puede comprender el deje de derecho natural entrometido en el desarrollo final del Estado en Hegel por mucho que quisiera eliminarlo. 
El deber no podía ser un «formalismo vacío» a la manera del imperativo categórico kantiano, sino que en rigor había de concordar con el «actuar el derecho y cuidar el bienestar: el propio bienestar particular y el bienestar en determinación universal, el bienestar de los otros», ${ }^{8}$ con lo que el Estado, en cuanto realidad de la voluntad libre de todos encardinada en la eticidad, se torna sustancial. Sustancial en tanto bien particular de cada uno sin excepción: «posee la autoconciencia particular elevada a su universalidad», ${ }^{9}$ es lo racional en sí y por sí en su figura de la obediencia a la razón a través de la obediencia al deber, pero también es concreción, sustancia.

En él la libertad llega a su más alto derecho «frente al cual los particulares tienen el deber supremo de ser componentes del Estado», pues representa y completa los fines de los particulares. Pero, las maneras del Leviatán aparecen cuando esta unidad sustancial es fin en sí, y es que tan solo necesita de una complementariedad -la del fin- que encuentra enseguida, pues es él mismo. La primera razón plausible para esta apología de una soberanía con tintes westfalianos es que Hegel tiene muy claro cuál es la forma de gobierno adecuada al fin del Estado y, se trata de una forma que no todos los Estados modernos lucen. ${ }^{10}$

El sueño de Aristóteles es seguido únicamente en las consecuencias que éste pudo llegar a temer. Con él, aceptará Hegel implícitamente el zôon politikón

$8 H W .7,251 ; F D, 141$. Marx acota esta idea como antesala de una obra temprana en su pensamiento, la Crítica de la filosofía del Estado de Hegel de 1843. «[...]la libertad concreta consiste en la identidad (necesaria, doble) del sistema del interés particular (de la familia y de la sociedad civil) con el sistema del interés general (del Estado) [...]» (MW. 1, 203; traducción en Marx, K. Crítica de la Filosofía del Estado de Hegel. Comentario a la sección 261. Edición de Ángel Prior Olmos. Traducción de Jose María Ripalda. Biblioteca Nueva. Madrid, 2002. p.68. Abreviado como $\mathrm{CH}$ seguido de la página) ¿A qué hablar del individuo en ese caso? La palabra clave que resalta Marx es la de dependencia, como necesidad del carácter determinado del Estado que precisan las instancias subordinadas de libertad...

$9 \quad H W .7,399 ; F D, 245$.

10 La forma específica a la que él se refiere es la de la monarquía constitucional. La Constitución figura como aquél derecho interno al Estado que, lejos de reducirse a vacuos sistemas de leyes y sus deducciones, adoptan en el mundo hegeliano los rasgos de la vida concreta, orgánica y organizada de la comunidad. El Estado es pues un todo viviente y, su Constitución es el Volkgeist que lo sustancializa. Como tal, debe resistir a cualquier invasión de su autonomía y toma la «forma más perfecta» que es aquella que ha aprehendido la modernidad implícita en el principio de soberanía. Lo individual en lo total. (vid. $H W$. 7, 444; FD, 277); vid. MW. 1, 224; $C H$ 94-95; Vale la pena echarle una ojeada al fragmento político número 26 de Friedrich Nietzsche para comprender los límites ideales de la hipertrofia estatal: «El Estado que no puede alcanzar su última meta se dedica a crecer de un modo monstruoso y considerable. [...]» (Nietzsche, F. Fragmentos póstumos sobre política. Edición y traducción de José Emilio Esteban Enguita. Editorial Trotta. Barcelona, 2004. p. 64) 
como plena libertad y reconciliación del hombre consigo mismo. Pero, aunque ésta presente en todas sus páginas, desdeñará la idea allí presente (y que aparece casi como un desideratum) a falta de nombre, decidido a ignorarla: allí está también el zôon koinonikón. ${ }^{11}$

En el momento en que hacen su aparición las motivaciones desde los otros, la universalidad del bien y la sintonía entre la voluntad particular y la universal, y las filiaciones de raigambre iusnaturalista se presentan, sale de la misma escena la juventud contestataria al maestro de Berlín.

Max Stirner estará entre ellos.

\section{ANARQUía Y AKRASÍA. CONTRADICTIO IN TERMINIS}

Estado y eticidad realizan la conciencia individual del individuo en el espíritu de su pueblo, «el individuo se libera de sí mismo» y es concretamente en la comunidad. Curiosa paradoja. Debe negarse como voluntad subjetiva libre para determinarse como voluntad objetiva universal y así ser realmente libre. El término redención hace referencia en Hegel al momento en el que la libertad que ha sido abstracta se limita-se niega- por mediación de su medición respecto de los que son deberes éticos, obligatorios, sociales. Familia, sociedad civil, Estado son las coordenadas, como se puede apreciar, en que se encuentra al individuo, entretejido en el haz de relaciones, en la relación entre esferas políticas; así, éste es el maximum de libertad, de lo particular a lo universal sin «saltos». Allí donde llegan las esferas de pertenencia de cada individuo -su anatomía social-, allí llega él mismo y su poder. Pero, como en el caso de la mosca atrapada en la tela de araña su acción es la que llega más lejos a través de hilos, que son el comienzo de su disolución entre los mismos. «Para quien resulta una necesidad moral y lógica imaginarse los caminos de salvación universalísticamente [...] parece que es una ley de juegos del lenguaje universalista que, en sistemas de inclusión universal, el exclusivismo sólo puede ser superado por negación [...]».12

$11 \mathrm{Al}$ «animal político» que construyera Aristóteles como modelo de hombre sucede alrededor del año 320 a.C., con el imperio de Alejandro Magno, el modelo de «animal común», de la koiné, que se refleja en el infinito de la esfera exterior del Imperio. Las escuelas helénicas retratan perfectamente la reacción de enclaustramiento frente a lo ominoso del vasto cosmos construido a través de las consignas referidas al Jardín, la Naturaleza y el Pnéuma universal, amén del escorzo hacia la animalidad que contrapuntean los cínicos, diluyendo sea cual sea el epíteto que acompaña al zôon. vid. a este respecto el modelo del «kosmopolités» que se dibuja en Sloterdijk, P. En el mismo barco. Capítulo 2. Ed. Siruela. Madrid, 2002. p. 36 y ss.

12 Sloterdijk, P. «Arcas, murallas de ciudad, fronteras del mundo, sistemas de inmunidad» en Esferas II. Macrosferología. Capítulo 3. Traducción de Isidoro Reguera. Editorial Siruela. Madrid, 2003. p. 228. El subrayado es mío. 
Y es negación misma lo que recae sobre el individuo al ejecutarse la contraposición entre derecho abstracto y eticidad y, abogar por el segundo. Es así que verdaderamente toda determinación implica una negación. Literalmente nos es posible decir que, en este caso, la una anula como contenido del derecho a la otra, y, la coloca como concepto aislado en el supuesto de que queramos verla fuera del respaldo del sistema de lo ético. Acaba así siendo aplicada sobre este concepto la misma consideración dedicada a la ley moral kantiana: peca de una vacuidad angelical. Y es que, cuando decimos que «buscamos» derecho lo decimos en el sentido del que se dirige «al tribunal con ese fin. ¿A cuál? A uno real, papal, a uno popular, etc. ¿Puede un tribunal sultánico aplicar un derecho distinto al que ha promulgado el sultán? ¿Puede darme derecho cuando busco un derecho que no concuerda con el derecho sultánico? [...] ¿Qué busco entonces en ese tribunal? Busco derecho sultánico, no mi derecho; busco un derecho... ajeno. Mientras concuerde este derecho con el mío, encontraré, ciertamente, el último en el primero». ${ }^{13}$

Sólo en el caso de que, por azares del destino, se de la casualidad de que lo que el derecho estatal me presenta como mi derecho se avenga realmente a lo que es mi voluntad, podré considerarme satisfecho y de acuerdo conmigo mismo.

Este problema, el de la causalidad que no debe serlo, es el de Stirner. Es de todo menos sencillo. Su falta de simplicidad se basa sin embargo en un supuesto muy básico: el olvido de la posición desde la cual queremos. Visto de esta manera las dificultades sólo pueden surgir en el uso de los conceptos. En su práctica es una forma más de la llamada confusión entre el carácter de lo público y lo privado, pues, en la medida en que esta confusión reclama una determinación justa de dos soberanías -la que compete al ordenante como representante y la que le pertenece como persona privada- lo que se dirime en aquel primer caso es si se pueden localizar las fuentes, a veces confluyentes, de lo que es mío y de lo que corresponde a otro. La voluntad tiene en sus determinaciones un objeto, que es el contenido de lo que desea y, allá donde arriba éste arriba su consecución si no hay resistencias. El error que se destaca es el de tomar por mía una determinación ajena y darle un asentimiento como si fuese una decisión propia. En la función política se asimila lo que un individuo podría considerar como su derecho a lo que otro individuo establece como derecho. Esto es, viene a ser una identificación de la actuación de ambas partes y, el triunfo de la una sobre la otra depende en última instancia del «tribunal privado» de cada individuo y la legitimidad con que distingue ante éste tanto la elección propia como la extraña. Max Stirner ha señalado con un término sumamente apropiado esta operación de derecho: el asunto ronda la idea de si reconocemos o no nuestro derecho. 
Los términos 'acracia', 'anarquía', 'individualismo'... no pueden sino venirnos a la cabeza llegados a esta encrucijada. ¿Obro por mí o por otro? Y esto, según Stirner, es lo mismo que preguntarse si soy por mí o por otro. Los conceptos citados sirven como eje de discusión de las variables con que se puede responder a estas interrogaciones.

«Los Estados duran mientras exista una voluntad dominadora y esa voluntad dominadora se considere idéntica con la propia voluntad. La voluntad del soberano es...ley.¿De qué te sirven tus leyes, si nadie las cumple? ¿De qué te sirven tus órdenes, si nadie se deja ordenar?».14

La estructura, la ley y la orden, el acuerdo o concierto, sólo pueden mantenerse -aunque hablar de sostenerse es quizás una nomenclatura más acertada en lo que al tema se refiere- si se supera el grado mínimo de disensión que implica el desmembramiento de un objeto común en pro de muchos particulares. Tanto la sociedad civil como el Estado han de acabar fundando alguna clase de generalidad o universalidad en el querer para conseguir por el mismo procedimiento la reafirmación en éste por parte de todos y cada uno o, de todos menos unos pocos de entre los individuos que intentan formalizarse en la unión. «Formalizarse» porque es impensable una presencia concreta, constante y sustantiva de cada uno de los miembros que se «asimilan» en cada situación en que la ley deba mediar entre alguna de las partes. Un contenido de la misma que sea ubicuo y aplicable como posibilidad respecto de los miembros que representa, no obstante, es pretensión primaria. La diferencia entre una orden acatada y una contestada sólo puede radicar en ese caso en la aceptación como propio o extraño del contenido que dicha orden contiene. Y es que, ni siquiera las «ordenes», las reglas, con las cuales yo puedo pretender medirme importarán nada en el caso de que no las lleve a cumplimiento yo mismo. «¿De qué sirven tus leyes, si nadie las cumple?», esto es: si nadie, incluso tú, las cumple.

Esto ha sido ya bautizado desde antiguo. Se le ha llamado 'akrasía' -y por intemperancia se suele traducir ${ }^{15}$ - y viene a ponerse en el supuesto de la paradójica situación, de la que sin embargo todos hemos tenido noticias, en la que un individuo convencido de sí es incapaz de acatar sus propias directrices. Un individuo, conociendo sus fines llega a despreciar los medios para conseguirlos sabiéndolos los únicos. Esto sólo adquiere algún sentido en el caso de

14 Ibid. p. 246

15 El término es conflictivo de cara a su isomorfía con respecto al original griego. La traducción común suele volcarlo de esta manera desde las primeras ocasiones, como es el caso de la traducción de Julián Marías. Un intemperante puede asimilarse a aquél caracterizado por su debilidad de ánimo, en el temple. Templanza es un concepto mucho más conocido proveniente de los textos platónicos - una de las virtudes que anda buscando Sócrates en su eterna formación. Ésta es la marca de aquél que se arredra ante sus propias determinaciones, esto es, que se niega o se desdice. 
que el individuo únicamente crea conocer sus motivos. La opción alternativa es un sinsentido: que se pueda querer el fin pero no los únicos instrumentos que hay para conseguirlo. El Derecho «tiene que ser vinculante para mí, puesto que ha sido introducido por la razón humana, frente a la cual mi razón no es más que insensatez», ${ }^{16}$ esto es lo que gritan -según Stirner- los partidarios de la construcción estatal. Yo me represento bajo el epítome de la razón humana y, como humano, no puedo decepcionarla. Debo querer, con necesidad de obligación, aquello que es razonable, y, si no lo hago, entonces no puedo querer realmente el contenido de aquello que es contra la razón. « ¿Cuántas causas no debería defender! Ante todo la buena causa, luego la causa de Dios, la causa de la verdad, de la libertad, de la humanidad, de la justicia; además, la causa de mi pueblo, de mi príncipe, de mi patria; finalmente, la causa del espíritu y miles de otras causas. Tan sólo mi causa no debe ser nunca asunto mío. ‘Pues vaya con el egoísta que sólo piensa en sí mismo!'».17

Y es que el reacio, el indeciso y «el refinado», «el dispuesto a plegarse», se encuentran aún a falta de definir. Se hallan en vísperas eternas de formarse según su propia voluntad. Dejan que «se haga de ellos algo». ${ }^{18}$

Pero, «quien, para existir, deba contar con la abulia de otros, es una obra defectuosa de esos otros, al igual que el señor no es más que una chapuza del siervo. Si cesara el sometimiento, se habría acabado el dominio». ${ }^{19}$ El Estado, la sociedad comunitaria, el dominio del otro sobre mí, precisan de reconocimiento para estar presentes. Resulta curioso que justamente aquello que se caracteriza por ser «generador de derecho», instancia de reconocimiento, necesite a su vez de un reconocimiento por parte de aquellos sobre los que se coloca en posición de jerarquía. Son los individuos los que «ponen sobre sus rodillas» (de augere y auctoritas) al hijo reconocido de su espíritu: ya sea la idea, el prójimo, la comunidad, el señor. Autoridad y legitimidad, y así, de nuevo, el balance matemático adecuado para dotar de prerrogativas a cualquier gobierno pasa por el déficit de poder bajo el que se deben englobar sus ciudadanos. Todos -o todos menos unos pocos, los sostenibles- renuncian a parte de su hacer en beneficio de un tercero fuera de toda disputa. La demanda de la propia voluntad es la perdición de todo Estado y la única denuncia que peca de injusta -como con Hegel- por la razón más sencilla, que no puede ser sino la que abole toda estructura de justicia si es seguida por todo ciudadano: la disolución del gobierno por medio de una suerte de atomización de pareceres. Stirner, perspicaz en este

$16 U P$, p. 257. Cf. con Carroll, J. «The anarcho-individualist and social action» en Break-Out from the Crystal Palace. Routledge and Kegan Paul. London and Boston, 1974. p. 48 y ss.

$17 U P$, p. 33

$18 U P$, p. 231

$19 U P$, p. 246. El subrayado es mío. 
como en otros casos, sólo puede describir una situación tan llamativa al señalar la hipóstasis bajo la que entendemos el Estado construido por nosotros mismos, obra nuestra. El Estado tiene el deber de reclamar su existencia a través de la declaración bajo el signo del 'capricho' y del privilegio de toda aquella voluntad que desee volver a ser comprendida como propia.

\section{LA CASA DEL EsPíritu}

El Estado es un ente que en su abstracción pugna por su supervivencia. Al final, aquí cobra sentido la parábola que la tradición judía ha preparado acerca de ese autómata llamado Gólem. Para ello, nótese que según Stirner se necesita de la 'abulia' de aquellos sobre los que impera. Abulia que no es sino falta de voluntad, de decisión. Sin más, una enfermedad.

Recojamos a este punto aquel otro concepto emparentado con éste. La akrasía es una forma más de la explicación de la debilidad en la voluntad, pues no es más que el déficit de poder que mencionábamos. A pesar de que 'acracia' haya sido sinónimo de anarquismo debe entenderse muy bien la connotación que se le desea dar según el caso, pues es palabra límite que sirve tanto para dar como para quitar.

Hegel ha contribuido a la opinión -difícil de digerir-de que sólo se alcanza la verdadera libertad por mediación de la acción que se ha vuelto política en grado sumo. Ésta es aquella acción obediente, con lo que «iEl servidor obediente es el hombre libre! ¡Qué contrasentido más cruel!».20

Debemos considerar, nos cita Stirner, «qué hacen con $s u$ causa aquellos por cuya causa debemos trabajar, sacrificarnos y entusiasmarnos». ${ }^{21}$ ¿Renuncian a ella como se pretende que hagan aquellos que aún reciben el signo de la disidencia? En cuyo caso más bien estarían actuando, sin advertirlo los beneficiados, en la causa de éstos, de una manera altruista siempre.

¿O, más bien se hallan al final de la espiral de fines, en el fin común, recogiendo el balance de la suma del servicio de todos? Según la Teoría del Derecho que puede conocer Stirner, al final de toda acción se encuentra el motivo que propició la misma, y, éste, resulta ser uno siempre elusivo, que tiene su base en otro. En este marco se puede estar en el Estado, determinarse y concretarse,

$20 U P$, p. 146.

21 Ibid. p. 33. 'Entusiasmarnos', esto es, llenarnos de Dios o de Espíritu. Aquellos que están poseídos de Espíritu son viejos conocidos de Nietzsche en las páginas del Así hablaba Zarathustra. Los «Hinterwelters» son su presentación en sociedad, pero es que esa misma nomenclatura es utilizada y acuñada por Stirner en las primeras páginas de su texto: son «los de detrás del mundo» o los del mundo del espíritu, los metafísicos. Se puede seguir la pista de cómo pudo ser influido Nietzsche por la lectura de Stirner en Díaz, C. Ibid. p. 11 y ss. 
definirse con referencia al Estado, con lo cual «nos definimos en relación a ...», o, ser-en caso contrario-acreedores del adjetivo de 'injustos', 'inmorales', 'reprobables', 'transgresores de la legalidad', 'inhumanos' incluso llegado el caso, pues lo que va a traicionar esta hostilidad del Estado al nombrarme, al estigmatizarme, es que exige que yo sea «justo», «moral», «respetuoso con la ley», «virtuoso», en definitiva «humano». Lo exige con carácter de ley, dónde todas estas denominaciones se corresponden con la presuposición de que yo, puedo no serlo «y que podría ser considerado por él [...] un monstruo; me impone como un deber el ser humano» ${ }^{22}$ siendo el dudoso concepto 'ser humano' aquél que concuerda con que «no haga nada en lo que él no pueda imponerse; su existencia debe ser sagrada para mí. Entonces no debo ser ningún egoísta, sino un hombre 'honesto, honrado', esto es, un hombre moral. En definitiva, contra él y su existencia debo mostrarme impotente y sumiso». ${ }^{23}$ Abnegado, dice Stirner.

El andamiaje conceptual del Estado, convierte en un sinsentido el mismo ejercicio en que excluye a alguien bajo las acusaciones vistas, pues mantiene formalmente que puede designar algo fuera de sus propias categorías. Ser «inhumano» es algo de corte bien distinto a «no ser humano», al no corresponderse con el concepto acuñado, al traicionarlo, pero esto... propiamente no se puede decir. Queda fuera o dentro del concepto humano. Una de las dos cosas debe elegirse. La imagen mítica -el homo sacer-del derecho romano recordada por Agamben viene a ajustarse perfectamente con este procedimiento de inclusión/ exclusión que se abre entre la societas y lo alienum, lo extraño e incivilizado, una de esas pocas ocasiones en las que se muestra el lado salvaje y hostil de aquello que queda fuera de la ciudad.

Sólo si se admite que este criterio formal de designación de lo propio y lo extraño es fruto de un error categorial entra en juego el argumento crítico de Stirner. Se puede decir con él que la clasificación es inconsistente -hasta desde el punto de vista formal- en la medida en que pretende ser completa en sus juicios pero apela a conceptos que no pertenecen a su dominio. No deja

$22 U P$, p. 228; Stirner se va a encargar de colocar la duda como principio grave de racionalidad, que, como propedéutica para la decisión de un principio conforme a norma aleja todo fantasma de verdad individual. Ésta tiene que ser universal y común. El problema verdadero es que esta 'duda' no es para nada genuinamente metódica como se pretendía sino que es la duda que debe evitar todo creyente. Nadie debe dudar de la palabra de la ley, del prójimo, del ser humano, de la sociedad civil... Esta norma debe ser la de lo mejor, imbricada en el proyecto estatal que es el de comunidad perfecta. El camino de la racionalidad es pues el de la Bildung de la mejor sociedad, que ha de ser para ello moral. La verdad no puede lograrse en solitario ni poner en mi voluntad otra ratio que la del bonum universal una vez descubierto. vid. Ibid. p.123; vid. Carroll, J. «Stirner's redefinition of property» en Ibid. p. 134 y ss.

$23 U P$, Ibid. El énfasis es mío. 
de ser esto una variante de aquél caso en el que «aceptamos el juego» de las apariencias legitimándolo. Es en este sentido en el que se nos permite hablar de e-lusivo e i-lusivo (in-ludere) como «entrar en el juego». Este juego no es más que la lógica del discurso estatal.

La problemática de la anarquía que enarbola Stirner es la del que sólo juega a su juego, que, en la terminología de éste es el de su causa. Así recibe cada término su significado desde ésta, la única causa, que es la que limita en jerarquía cualquier determinación posterior. De ahí que el diálogo que extiende Stirner en El Único se acomode a tan sólo dos polos -es en sentido literal un dia-lógos- compuestos de dos partes que acentúan por tiempos cada uno de dos puntos de vista: El Hombre -a saber, cualquier hombre o, trágicamente, ningún hombre-y Yo-aquél que no es agotado en ninguna definición relacional. Jugar al juego de poder del Otro, al juego de categorías, que acaban mostrando su incoherencia a través de la propia existencia de los hombres, es comprar apariencia por realidad y penetrar en el mundo de los espectros, lugar donde el espíritu se hace carne sin dignificarla más allá de sus propósitos. Es ceder la realidad a otro que la ejercerá como en una suerte de metempsomatosis. Estos sujetos son los «enajenados», los poseídos de las páginas del Único. Lo más curioso es que esta transformación es obra de palabras que sólo a posteriori traen los hechos: la ley, la tradición, la costumbre ...

«El futuro queda reservado a las palabras [...] nada 'esencial' o 'sustancial' se somete a un cambio, por ello con más energía trabajan en lo que permanece, lo cual lleva el nombre de lo 'antiguo', de los 'antepasados', etc.».24

\section{LA INSTITUCIÓN DE CUALQUIER COSA}

El pasado y el futuro, que nos son traídos por el verbum desde el antes, se convierten en «lo sagrado». Lo sagrado es fruto de la unción del y, desde, el objeto ausente. Un objeto que no puede ser sometido a crítica, y que por ello permanece eterno en su dignidad, en su potencia legitimadora. Es sagrado aquello reconocido como tal y, retornando a la causa por el efecto, debemos poder reconocer que el concepto de lo sagrado es aplicado por mí, que yo soy el que sacraliza -canoniza- y que toda humillación debe desvanecerse en el conocimiento de esto. O bien, que yo soy sagrado, y por esto instituto en algunas cosas un «sacramento». A Stirner le viene bien cualquiera de los dos miembros de la disyunción.«Ante lo sagrado se pierde todo sentimiento de poder y todo valor, uno se comporta frente a ello como impotente y humillado. Y, sin embargo, ninguna cosa es sagrada por sí misma, sino por mi canonización, 
por mi sentencia, mi juicio, mi genuflexión, en suma, por mi...conciencia». ${ }^{25}$ Tras el mundo del espíritu se encuentran sus autores, conocedores o no de esta circunstancia.

La acracia y la akrasía se acercarán sólo en tanto en cuanto uno sea alejado de lo que puede y sólo tenga el derecho a la acción desde una posición que no es sí mismo. Este también es el problema de la terminología anarquista que no deja bien claro que lo que se destituye no es poder-krátos-sino a poderosos -arché, archai, archonte...

El poder no se crea ni se destruye, se distribuye.

Aparece la diferencia fundamental que existe entre los términos revolución e insurrección, dónde la distinción a dilucidar entre los mismos los aleja radicalmente de toda sinonimia que pudiera ocurrírsenos. «La primera consiste en una alteración radical de las circunstancias, del orden establecido o del 'status', del Estado o de la sociedad, por consiguiente, se trata de un acto político o social» ${ }^{26} \mathrm{y}$, por ello, conduce a la transformación de las relaciones de circunstancia, pero parte principalmente de la insatisfacción reinante en el corazón de los hombres y no del cambio fundamental de condiciones. Sin embargo, la insurrección pone como meta lo que ya es el inicio del movimiento: «una sublevación sin consideración a las instituciones que surgen de ella» ${ }^{27}$ y que, por tanto, no aspira a nuevas instituciones sino a no dirigir más, al no haber esperanza alguna en la canonización, la sacralización, la estatificación en lo permanente, la institucionalización... La libertad política tanto como la libertad religiosa no se venían a referir a la libertad para con la religión, para con lo político, sino que hacían su signo en la expresión de una libertad sin intermediarios sólo bajo la condición de que se entre en la religión y no se carezca de ella, de que se entre en el Estado y no se viva fuera de él. La libertad política, religiosa, de conciencia, no nos dicen que «soy libre del Estado, de la religión, de la conciencia», sino que lo que aquí se dice es que el Estado es libre, que la religión es libre, que la conciencia es libre.

Esto significa que los poderes que dominan y someten sí son libres. ${ }^{28}$ Yo soy tolerado en la justa medida en que caigo bajo su égida. ¿Libertad individual? Por supuesto. Pero no significa que disponga de mis acciones enteramente, sino que estas son independientes de otros individuos, de otras personas. ${ }^{29}$

25 Ibid.p. 108.

$26 U P$, p. 386.

27 Ibid.

$28 U P$, p. 148; Löwith, K. De Hegel a Nietzsche. La quiebra revolucionaria del pensamiento en el siglo XIX. Marx y Kierkegaard. Traducción de Emilio Estiu. Editorial Sudamericana. Buenos Aires. 1974. p. 150.

29 Ibid.p. 149. 
Mi libertad, por tanto, será perfecta cuando sea mi poder. Es sólo a través de este ejercicio de autoafirmación como las líneas de fuerza se reconducen hasta las cercanías de la subjetividad particular. Lo que quiero me define, y lo que me define no puede sino pertenecerme. El nadir de la argumentación del Estado llega con la constatación de que existen expresiones «vacías de poder» al carecer del contenido que les daría sustancialidad. Con una estructura filosófica que remite veladamente como homenaje a Hegel, Stirner coloca lo real en lo efectivo. Lo que es «wirklich» es el actuar, que es lo que convierte a cada uno de nosotros en propietario de nuestras acciones, las cuales, parafraseando al poeta de la Hélade al hablar de Apolo, hieren tan lejos como pueden: «El poder es una gran cosa y sirve para muchas cosas, pues 'se llega más lejos con un puñado de poder que con un saco de derechos'. ¿Anheláis la libertad? ¡Necios! Tomad su poder y la libertad vendrá por sí misma. Ved quien tiene el poder, él 'está por encima de la ley'».30 La sentencia de Proudhon adquiere entonces proporciones míticas al final de esta argumentación, proporciones que distinguen una de esas pocas tesis con poder: «la propiedad es un robo»..., acotando: lo es de mi poder. Si las premisas son ciertas, es algo que se puede probar midiendo lo que habría de contener nuestro 'saco' de derechos para ser efectivos.

El engaño es aquí un pecado de conformismo.

A modo de conclusión: Esas malditas manías.

«Tienes vena de loco, ¡te falta un tornillo! Te imaginas grandes cosas y te figuras todo un mundo de dioses que está aquí para ti, un reino de los espíritus para el cual has sido llamado, un ideal que te hace señas. ¡Tienes una idea fija!». ${ }^{31}$

La manía es la llamada desde ultramar, desde lo inabarcable por la vista y que, sin embargo, se perpetua como morbidez en su fijación, en su repetición enfermiza. Son «manías» de la inteligencia esas ideas fijas demoradas en el pensamiento, y, como tema recurrente en gran parte de la filosofía del siglo XIX, las ideas se despliegan en las importancias de las acciones. Vuelta a su fijación..$^{32}$ Han de ser tratadas con cuidado. No es este un cuidado respetuoso, sino que me refiero, como parece indicar Stirner, al cuidado que se le debe tener a los especímenes peligrosos: es más bien el cuidado de nosotros con respecto a ellas. El peligro al que nos exponemos frente a toda idea que precipita a la acción con necesidad es el de la disolución de lo real en ella. La disolución más acertada de Hegel retoma como consumación y ejemplo para su tarea un dato que a él le pareció relevante y que es el espejo en el que se mira para poder disputar consigo

$30 U P$, p. 215. El subrayado es mío. Nótese que el poder es «cosa», efectividad.

31 Ibid.p. 76.

32 Cf. con Kropotkin, P. «La acción» en Historia de la Revolución Francesa. Capítulo tres. Ediciones Vergara. Barcelona, 2005. pp.29-30. 
mismo la pertinencia de las categorías empleadas: es el cristianismo límite de la forma ideal en tanto ha sido capaz de implementar en el ámbito del Espíritu, de las ideas, el ser de la objetualidad. A través del sacramento, que no es sino una entrada canónica en el mundo, la palabra «empeña» al individuo. Para esto no hay medias tintas: «el perfecto entusiasmo - pues uno no se puede detener en el débil e incompleto- se llama fanatismo», ${ }^{33} \mathrm{y}$, por qué no, fantastismo.

Ser egoísta, sin embargo, es el término contrario al de entusiasmado, al poseído, que es el maniático. Estos son tipos de alienados, alejados de su morada, que es el éthos que algunos de los interesados en filosofía moral han encontrado en sus etimologías como el lugar de recogimiento dónde se concentra el núcleo de las acciones, de la vida y de la suerte de cada uno: referencia al hogar del que se expulsa al entusiasta, precisamente para que sea ocupado por el espíritu. Así somos huecos, hueros de ánima, a saber, de animación, de acciones, y en este punto flaco en que se nos coloca como continentes de lo superior al cuerpo, entra el egoísmo teórico que no atribuye valor absoluto a ninguna causa. Por mejor decir, no atribuye valor in-soluble a causa alguna. Todas pueden ser reducidas con esa extraña química de la crítica de la crítica crítica a su núcleo irreductible, y este es la nada desde la que se mueve toda actividad propia -no por cuenta aliena. ${ }^{34}$

El juego entre $a b$-suelto y ab-soluto es el de lo refractario y lo atomizable. La reducción atómica hasta sus últimos elementos, sus causas, conduce como reseña Stirner a que Yo no sea Nada sin Causas. Pero, como si una vez más Kant quisiera asistir desde la distancia -nunca mejor dicho transcendente- a aquellos que quisieron matizar el pretendido remedo del kantismo que es el Idealismo, decir Yo es lo que inaugura el reino de la libertad, auténtico Grundloss desde el que se es, y, origen de todas las causas. La toma de posición kantiana con respecto al problema de la identidad personal o la apercepción transcendental no es sino la «crítica» del límite, de las condiciones de posibilidad, del decir Yo. Como se muestra allí, «Yo he puesto mi causa en la nada». Esta es la forma

$33 U P$, p.78. De ahí que la lógica que se le exige al fanático sea la del converso, la del convencido de la verdad de la buena nueva para el que no puede existir el pecado de la duda... vid. Kropotkin, P. «Los anarquistas» op. cit. pp.313-318.

34 «Crítica crítica» era el interés de los hermanos Bauer a la hora de demarcar aquello que la tradición teológica había sustraído al Hombre, crítica de la crítica crítica era lo que se trataba de hacer en La sagrada familia de Engels y Marx como novedad y, lo que sin embargo, llevaba haciendo Max Stirner desde antes en las páginas de El Único. vid. Löwith, K. Op. cit. p.149 y 151. La crítica que le va a dedicar Marx en la citada obra amén de en La ideología alemana es, no obstante el reconocimiento de su argumento, la inconsecuencia de una crítica de ideas que sin embargo es incapaz de desembarazarse de las relaciones reales de constricción: Stirner es el ideólogo más radical de la sociedad burguesa decadente, tomada como una de 'individuos aislados', incapaz de librarse de las cadenas reales de la existencia... Ibid. p.152. 
$a b$-soluta del Yo: colocarlo en un «lugar» que es ningún sitio. Cualquier causa me pertenece o está por mí y es imposible identidad alguna del «yo» que no tenga esta conciencia de la experiencia.

Las fiestas saturnales de las que nos habla Nietzsche precisamente en el comienzo de su obra literaria son traídas en toda su significación desde la Roma de los césares: ha habido una mascarada del hombre con respecto al pensamiento y se ha acabado la excepción. Todo Estado fuerte es en detrimento del individuo sano, que goza de salud pública o privada y, por supuesto, el argumento inverso cae por su propio peso. Es una forma más de las tensiones que se derivan del par finito-infinito. Involucrados en lo infinito no sorprende que la universalidad de la idea y el amplio seno del Estado nos conduzcan psicológicamente a la calma e ingravidez con que caracterizara Nietzsche al mar del Zarathustra. De igual manera, toda acción, en tanto posición-Tathandlung-es un hecho que se opone a otros hechos. Implica una reacción. La facilidad de las resistencias o su oposición en el conjunto de las acciones estriba en el caso de que sólo haya una legitimada, que es la que se mueve con libertad en el universo o en el de que todas las acciones se muevan en direcciones complementarias.

El caso Stirner presenta la posibilidad que este conjunto de regulaciones del móvil perfecto no parece contemplar. Sólo implica avanzar desde la primera a la tercera ley de Newton e interpretarla en clave existencial : hay acciones que son contestadas por otras de sentido contrario, y que suponen una composición de las mismas. En un universo con miedo al vacío, desde luego que las hay. En el devenir social del hombre, es inevitable que mi afirmación apunte en alguna dirección irrepetible y por ello enfrentada a cualquier otra con el mismo punto de aplicación. No nos puede extrañar en este caso que, precisamente, la última e inacabada obra de Stirner se llame Historia de la reacción... ${ }^{35}$

Ricoeur le ha dado un par de vueltas a esa relación entre finitud y culpabilidad que sería conveniente invocar al ambiente. Sin embargo, la culpabilidad puede tomar las riendas desde el argumento contrario, a aquél que nos reclama responsabilidad y respuesta por nuestra deuda-empeño- con otro, momento preciso en el que se ata el individuo a la verdadera finitud, aquella que presta la infinitud de la libertad. Mi poder.

¿No nos es lícito en ese caso hacer una llamada urgente a las palabras que inducen la autonomía del individuo en su querer y obrar?;No es acaso autoculpable toda minoría de edad en un ser maduro de razón?

Es en ese caso necesario retocar de nuevo un concepto equívoco.

Stirner no es un megalómano en ese sentido en el que la manía se prolonga ilegítimamente en la única gran idea que los defensores de las «grandes ideas»

35 vid. Stirner, M. Geschichte der Reaktion. 2 Abteilungen in 1 Band. Neudruck der Ausgabe Berlin 1852. Scientia Verlag Aalen. Berlin, 1967. 
prohiben, la idea de que un individuo pueda obrar absolutamente, sino que se le puede dar una vez más la vuelta al término en un sentido más ajustado a la realidad. Stirner se marca con el distintivo del egoísta que quiere saber y creer que la manía que le obsesiona es aquello que, por ser insoluble, opaco a la crítica, punto trascendental, no es que sea «grande» sino que no puede ser más pequeño.

Más que un maníaco Stirner ha encarnado otro modelo de afección que ya conocieron los griegos pero que no sancionaron con el oprobio, la megaloprepéia, traducida en la Ética a Nicómaco como «magnanimidad» y que ya era vieja conocida de Platón en las figuras de Calícles y Trasímaco... la virtud pretendida de exigir para uno aquello por él merecido.

Ni más, ni menos.

Ricardo Gutiérrez Aguilar. CSIC (Departamento de Filosofía Teorética)-Universidad de Murcia. Miembro del Comité Editorial de la colección ‘Theoria cum Praxi' en la editorial Plaza y Valdés.

Línea de investigación:

Siglo XIX, Idealismo, Kant, Schopenhauer.

Publicaciones recientes:

«Complejo a Voluntad. Un diálogo Morin-Schopenhauer», en La filosofía y los retos de la complejidad. III Congreso Internacional de la Sociedad Académica de Filosofía. Eugenio Moya y Ángel Prior Olmos (coords.), Servicio de Publicaciones de la Universidad de Murcia. (ISBN 978-84-8371-654-0).

«Europa y la fenomenología» (Ricardo Gutiérrez Aguilar y José Miguel Hernández Mansi1la), en La cohesión en Europa. Los valores de la Unión, CARM editores. Secretaría de Acción Exterior de la Comunidad de Murcia. (D.L. MU-734-2007)

Dirección postal:

C/Sargento del Río Llamas 3, 1º 03009 Alicante (Alicante)

Direcciónelectrónica: megaloprepeia@hotmail.com 
